\title{
Correction: Hyperbaric oxygen can induce angiogenesis and recover erectile function
}

\author{
Amir Hadanny $y^{1,2,3} \cdot$ Erez Lang ${ }^{1,2,4} \cdot{\text { Laurian } \text { Copel }^{2,5} \text { - Oshra Meir }}^{1} \cdot$ Yair Bechor $^{1} \cdot$ Gregory Fishlev $^{1,2}$. \\ Jacob Bergan ${ }^{1,2}$ - Mony Friedman ${ }^{1} \cdot$ Amnon Zisman $^{2,4}$. Shai Efrati ${ }^{1,2,6,7}$
}

Published online: 9 July 2018

(c) Macmillan Publishers Limited, part of Springer Nature 2018

Correction to: International Journal of Impotence Research; $\quad$ https://doi.org/10.1038/s41443-018-0023-9; published online 18 May 2018.

The original version of this Article omitted the author Friedman M., MD from the Sagol Center for Hyperbaric
Medicine and Research, Assaf Harofeh Medical Center, Zerifin, Israel.

This has been corrected in both the PDF and HTML versions of the Article.

Amir Hadanny

Amir.had@gmail.com

1 Sagol Center for Hyperbaric Medicine and Research, Assaf Harofeh Medical Center, Zerifin, Israel

2 Sackler School of Medicine, Tel-Aviv University, Tel-Aviv, Israel

3 Bar Ilan University, Ramat Gan, Israel

4 Urology Department, Asaf Harofeh Medical Center, Zerifin, Israel

5 Radiology Department, Asaf Harofeh Medical Center, Zerifin, Israel

6 Research and Development Unit, Assaf Harofeh Medical Center, Zerifin, Israel

7 Sagol School of Neuroscience, Tel-Aviv University, TelAviv, Israel 